\title{
Effect on mechanical properties of Rice Husk/E-Glass polypropylene hybrid composites using Sodium Hydroxide $(\mathrm{NaOH})$
}

\author{
Kannan Rassiah ${ }^{1,}{ }^{*}$, M. M. H Megat Ahmad ${ }^{2}$, Aidy Ali ${ }^{3}$ \\ ${ }^{1}$ Department of Mechanical Engineering, Politeknik Port Dickson (PPD), Negeri Sembilan, Malaysia \\ 2, 3 Department of Mechanical Engineering, Universiti Pertahanan Nasional Malaysia (UPNM), Kuala \\ Lumpur, Malaysia
}

\section{Index Terms}

Polypropylene

Rice husk

E-Glass

Hybrid Composite

Received: 7 May 2016

Accepted: 28 May 2016

Published: 12 August 2016

\begin{abstract}
This paper presents the development of hybrid composites' mechanical properties. In the experiments carried out, Polypropylene (PP), Rice Husk (RH), and short E-Glass (EG) fibers are prepared through the process of melt-mixing technique at $175^{\circ} \mathrm{C}$ for 8 minutes and 50rpm rotor speed using an internal mixer (Haake Rheomixer Machine). The hybrid composites made are prepared in various ratios of fiber weight fractions varying up to $60 \%$ where the treatment of rice husk using $2 \%$ concentration of Sodium Hydroxide $(\mathrm{NaOH})$ to improve the interaction and adhesion between the nonpolar matrix and the polar lignocellulosic fibers. The specimens are analyzed by different techniques, such as tensile test, impact test, hardness test, and Scanning Electron Microscopy (SEM). The presence of $\mathrm{NaOH}$ in rice husk for $15 \%$ indicates higher tensile strength and impact strength, while the tensile modulus and hardness strength are, however, reduced. The morphology results support the tensile properties that indicated the interaction between the PP and fibers with $\mathrm{NaOH}$. These results recommend that rice husk and E-Glass fibers are a viable alternative to hybrid-based reinforcing fibers as long as the right processing conditions are applied and used in the applications.
\end{abstract}

(C) 2016 The Author(s). Published by TAF Publishing.

\section{INTRODUCTION}

Historically, the choice of plastic is the major concern for an addition and enhancement of human needs in various sectors. A plastic material has been chosen in many applications because of being light weight, cheap, durable and easily being processed to desired forms.

* Corresponding author: Kannan Rassiah

E-mail: kannan@polipd.edu.my; kannan780915@gmail.com
However, natural or synthetic fibers such as kenaf, bamboo, sugarcane, banana, coconut coir, and palm oil have been started to be used by many researchers [1], [2], [3], [4], [5], [6]. These natural fibers are especially being sought since the production of composites/hybrid using natural substances as reinforcing fillers is not only inexpensive, but also able to minimize the environmental pollution caused by the characteristic biodegradability [7]. 
The facts show that, natural fibers are not totally free from the problems. Due to being a hydrophilic material, they do not well interact with commodity polymers, such as low density polyethylene/thermoplastic sago starch [8]. Among natural fibers, rice husk is chosen in the study. The husk is the outer covering of paddy and accounts for $20 \%$ of its weight [9]. Rice husk is removed by rice milling and it contains $35 \%$ of cellulose, hemicelluloses $25 \%$, lignin $20 \%$ and ash $17 \%$ (94\% silica) by weight [10]. Figure 1 shows scanning electron microscope picture and the element of pure rice husk in hydrophilic.

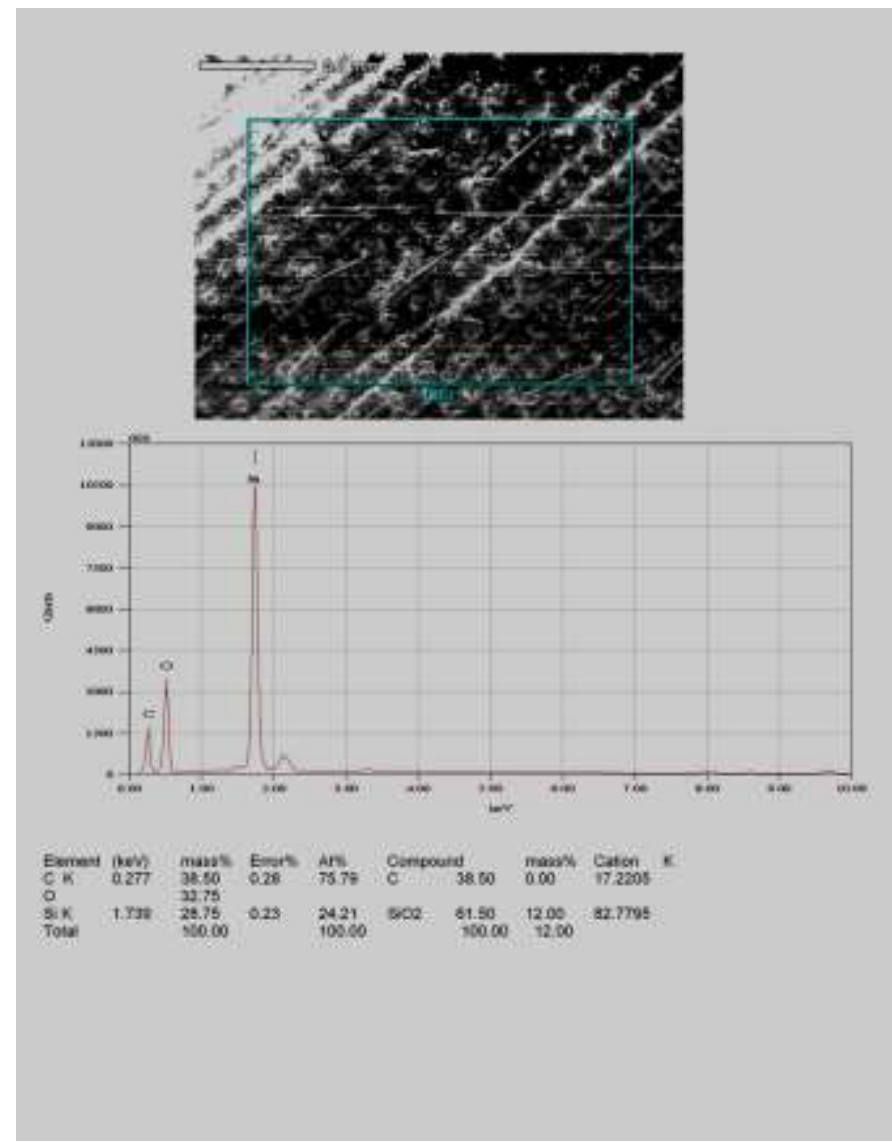

Fig. 1. Pure rice husk

Based on aforementioned, due to the result findings of polymer/natural fiber compound do not possess satisfying properties, therefore this study will review and focused on investigation through the approaches developed in order to improve compatibility of natural fiber filled polar and non-polar synthetic polymers. The study is also focused on the effect of mechanical properties of Rice Husk/E-Glass Polypropylene Hybrid Composites using Sodium Hydroxide. Finally, the evaluations come on with the best hybrid composition among matrix and reinforcement.

\section{MATERIAL}

The materials used in this study are "Polypropylene" (PP) as the matrix material, Rice Husk $(\mathrm{RH})$ as well as a strengthening of E-Glass fibers.

\section{A. Polypropylene}

Polypropylene (PP) has been used as matrix materials in the manufacture of polymeric materials. The Polypropylene used in the form of a "pallet", type of Polypropylene TITANPRO 6331 with Melt Flow Rate at $230^{\circ} \mathrm{C}$ and Density $0.9 \mathrm{~g} / \mathrm{cm}^{3}$ shown in Figure 2 .

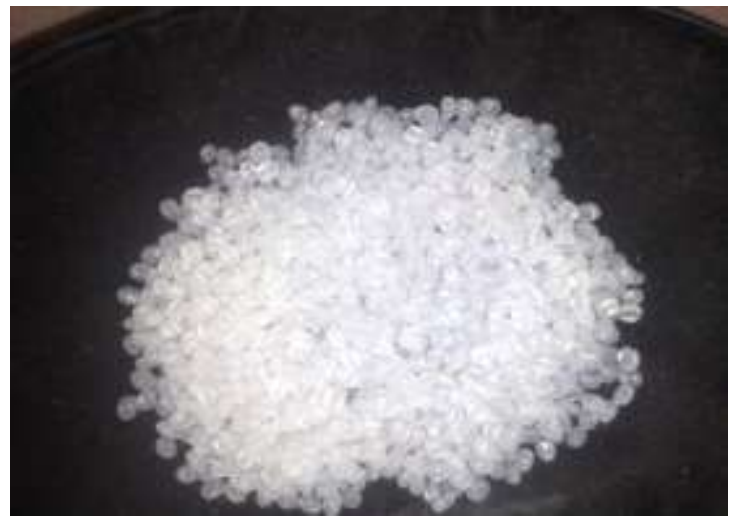

Fig. 2. Polypropylene (PP)

\section{B. Rice Husk}

Rice Husk (RH) was obtained from the rice field Alor Star, Kedah, (Malaysia). Its moisture content is $13 \mathrm{wt} . \%$ where the granular sizes ranged are from 500 to 1000 $\mu \mathrm{m}$, with an average granule size of $800 \mu \mathrm{m}$ as shown in figure 3.

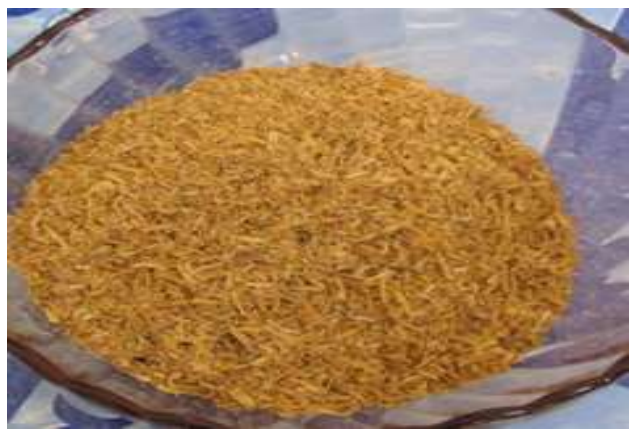

Fig. 3. Granule Rice Husk (RH) 


\section{E-Glass}

The synthetic fiber used in this research is E- Glass a fiber (E2- 4533 6000) was supplied by DK composite. The major constituents of E- Glass are silicon oxide (54 wt.\%), aluminium oxide (15 wt.\%), calcium oxide (17 wt.\%), boron oxide (8 wt.\%) and magnesium oxide (4.5 wt.\%). E- Glass fiber has an elastic modulus of $72.5 \mathrm{GPa}$ and possesses a density of $2.59 \mathrm{gm} / \mathrm{cc}$. The $6 \mathrm{~mm}$ was cut to obtain the fiber glass size.

\section{Process}

The formulation for polypropylene, rice husk and EGlass fiber is divided into six main compositions ratio as shown in Table I.

TABLE 1

HYBRID COMPOSITIONS RATIO OF POLYPROPYLENE, RICE HUSK \& E-GLASS FIBER

\begin{tabular}{cccc}
\hline Sample & $\begin{array}{c}\text { PP } \\
\text { (wt. \%) }\end{array}$ & $\begin{array}{c}\text { RH } \\
\text { (wt. \%) }\end{array}$ & $\begin{array}{c}\text { E-Glass } \\
\text { (wt. \%) }\end{array}$ \\
\hline 1 & 100 & 0 & 0 \\
2 & 40 & 0 & 60 \\
3 & 40 & 60 & 0 \\
4 & 40 & 30 & 30 \\
5 & 40 & 15 & 45 \\
6 & 40 & 45 & 15 \\
\hline \hline
\end{tabular}

\section{E. Treatment}

Figure 4 shows the treatment process of rice husk. First, rice husk is washed and boiled in the boiling water with the $1000 \mathrm{C}$ temperature for about 1 hour (figure 5 : scanning electron microscope picture and the content of element).

Second, they are forwarded to soaking process for 2 hours with $2 \%$ concentration of Sodium Hydroxide $(\mathrm{NaOH})$ as (figure 6: scanning electron microscope picture and the content of element). The next process is drying the rice husk under the sunlight for 72 hours. Before manufacturing process of the sample, the last process is grinding rice husk which has been dried as shown in figure 7.

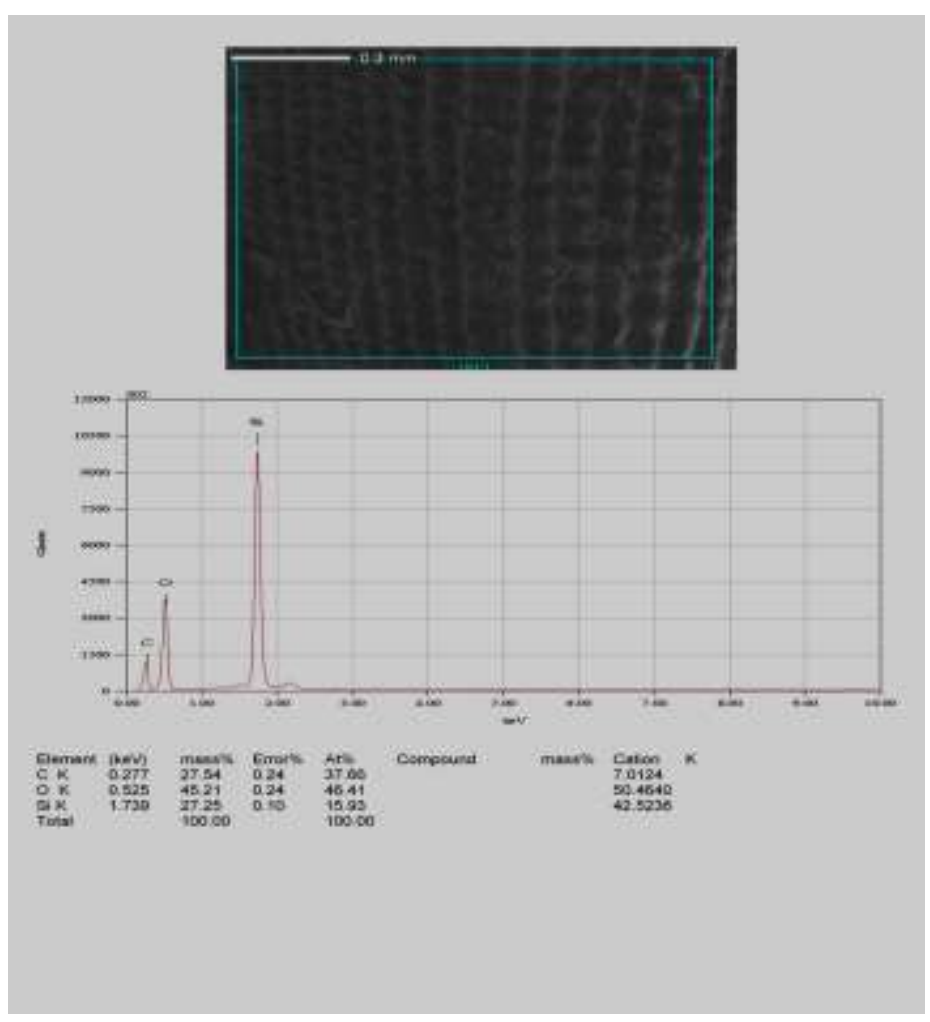

Fig. 4. The flow chart of rice husk (Treated)

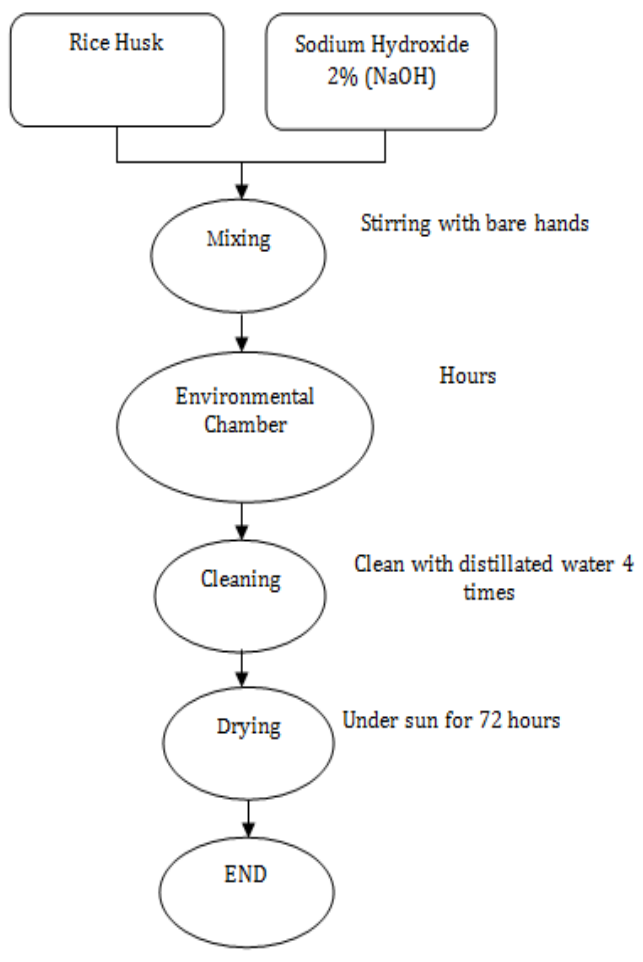

Fig. 5. Boiling treated rice husk 



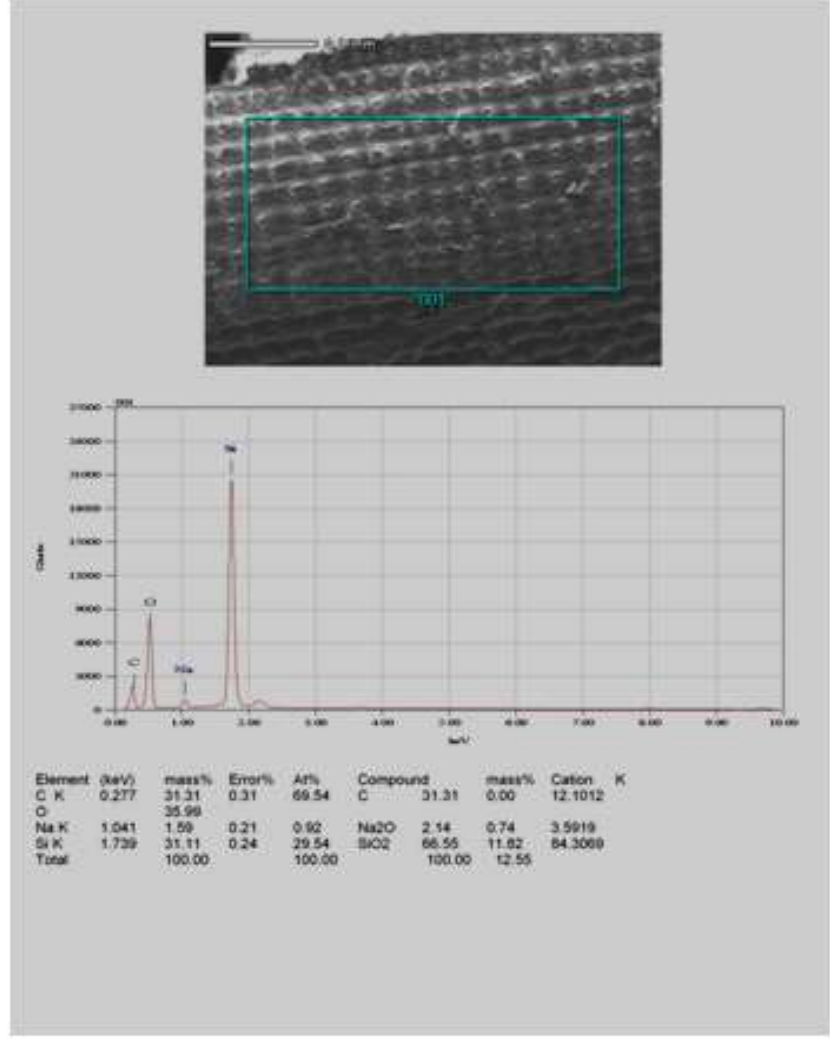

Fig. 6. (Naoh) Treated Rice Husk

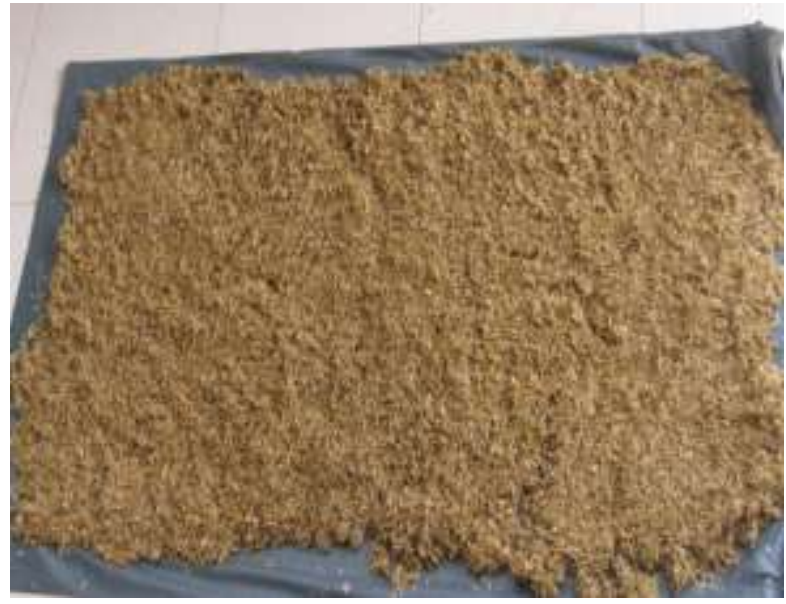

III. EXPERIMENTS

A thermal mixing process is carried out using a Thermo Haake Rheomix 600 OS internal mixer at a temperature of $180^{\circ} \mathrm{C}$ and a rotor speed of $50 \mathrm{rpm}$ for 8 minutes. Through this process, the mixtures of substances are expected better and more uniformly before goes to crusher machine in order to produce a standard particle size $2 \mathrm{~mm} \times 2 \mathrm{~mm}$. The final stage of the composite preparation process in this research is the hot pressing (figure 8). The hot pressing process is carried out at a temperature of $180^{\circ} \mathrm{C}$ for 10 minutes, and the mixture was then cooled under room temperature 15 minutes. The final products are in the form of plates with dimensions of $200 \mathrm{~mm} \times 200 \mathrm{~mm} \times 2$ $\mathrm{mm}$ and prepared into the cutting pieces as required by ASTM standard for mechanical testing.

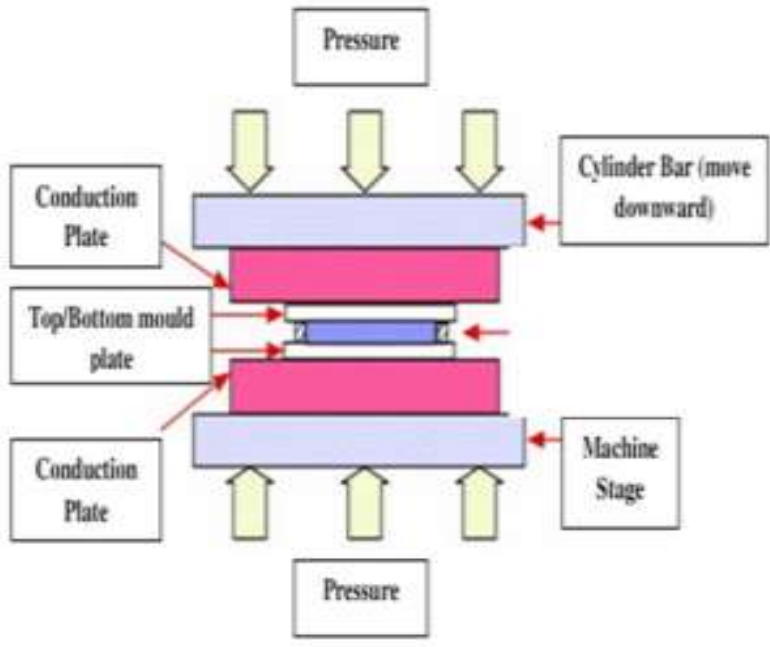

Fig. 8. Schematic of hot press

\section{A. Tensile Testing}

To cut the sample in the dog-bone shaped, a sample cutter is used. On this, seven samples made of PP/RH/EGlass hybrid composition with dimension of samples $125 \mathrm{~mm} \times 12.7 \mathrm{~mm} \times 2 \mathrm{~mm}$ are then tested according to ASTM standard D638. The tests were performed at $25 \pm 3^{\circ} \mathrm{C}$ with $50 \%$ of humidity and failure under tension at a cross head speed of $5 \mathrm{~mm} / \mathrm{min}$ using Shimadzu Universal Testing Machine. Tensile strength and modulus were recorded. Here, the morphology of the cracked surface is observed by using Scanning Electron Microscopy (SEM) at three types of magnifications, which are 22X, 100X and 500X, consists of topographical, morphological and composition pictures.

\section{B. Hardness Testing}

The hardness tests are performed according to ASTM E-384. The Micro Hardness Vickers is used to measure the depth of penetration of loaded indenter in to the material. The tests were performed at $25 \pm 3^{\circ} \mathrm{C}$ with $50 \%$ of humidity. Average of night point has been taken from each composition. 


\section{Impact Testing}

The impact resistance test was carried out by using the "Pendulum Impact Tester Model: LS 22006-2" complete with hammer $25 \mathrm{~J}$ impact force and the operating conditions at $23 \pm 2^{\circ} \mathrm{C}$ with $50 \%$ humidity. The test conducted in accordance to ASTM D6110 in order to determine the values of Charpy Impact Strength $\left(\mathrm{J} / \mathrm{mm}^{2}\right)$. The seven specimens were placed horizontally on a sample holder, and then will be broken by the swinging pendulum. Before the experiment, the width and thickness of the sample is measured by using the "digital vernier caliper" in which the average values are recorded.

\section{Morphological Observation of Fractured Surfaces through SEM}

Scanning Electron Microscope observation was performed using Philips XL 30 ESEM operated at 20 to $30 \mathrm{kV}$. The fractured samples from the tensile test were first dried and coated with the gold using Sputter Coater Polaron E-5100 system. Dispersion state of RH/E-Glass fiber and the fracture mode of composites under the tensile loading were determined.

\section{RESULTS AND DISCUSSION}

\section{A. Tensile test}

The rice husk is filled with various mixtures of short E-Glass and polypropylene to produce hybrid composites. In general, results showed that tensile strength of the PP/EG/RH hybrid composite decrease with the addition of rice husk (figure 9). However, the tensile modulus of the hybrid composites displays different behavior (figure 10). The higher value of the tensile strength hybrid mixture PP, E-Glass, and rice husk is 7.9 MPa.

This refers to the objective priority of the research that is to find the best value of tensile strength for EGlass and the rice husk hybrid composition of the manufacturing process. The PP $40 \mathrm{wt}$. \%, E-Glass $45 \mathrm{wt}$. $\%$ and rice husk $15 \mathrm{wt} . \%$ mixture was observed and the tensile strength is higher compared to the other wt. \% hybrid compositions. It is proven by the result where the more percentage of rice husk show lower value in hybrid composition. It is because fiber reinforced composites have higher tensile strength than particlereinforced composites [11]. Furthermore, the less percentage of matrix/ synthetic fiber cannot reinforce well with natural fiber and it make facture if stress is applied and easy to slip off. The possible explanation for this different behavior could be due to the non- uniform dispersion of rice husk within the polymer matrix which impairs the mechanical properties [12], [13] and [14].

Mean while Figure 10 shows that modulus value is increasing when percentages of rice husk increased in $\mathrm{PP} / \mathrm{EG} / \mathrm{RH}$. The tensile modulus increased from 1074.5 $\mathrm{MPa}$ to $1345 \mathrm{MPa}$ from $15 \%$ to $45 \%$ rice husk respectively. The result showed that the incorporation of rice husk has resulted in the increasing of flexural modulus. The rice husk flour has restricted the mobility of the PP/EG matrix and synthetic fiber when load was forced onto the hybrid composite. Similar results were reported by [6] addition of rice husk and clay into the thermoplastic decrease the tensile strength but increase the modulus. Besides that, using rice husk flour in thermoplastic composite [15] determine that tensile strengths of the composites slightly decreased as the filler loading increased but tensile modulus improved with increasing filler loading. While increasing the rice husk ash loading in natural rubber/linear low density polyethylene blends resulted in reduction of tensile strength, but increased tensile modulus [16]. According to [17] the weak filler distribution, poor filler matrix interaction, and large agglomerated particle size, caused those properties to decrease.

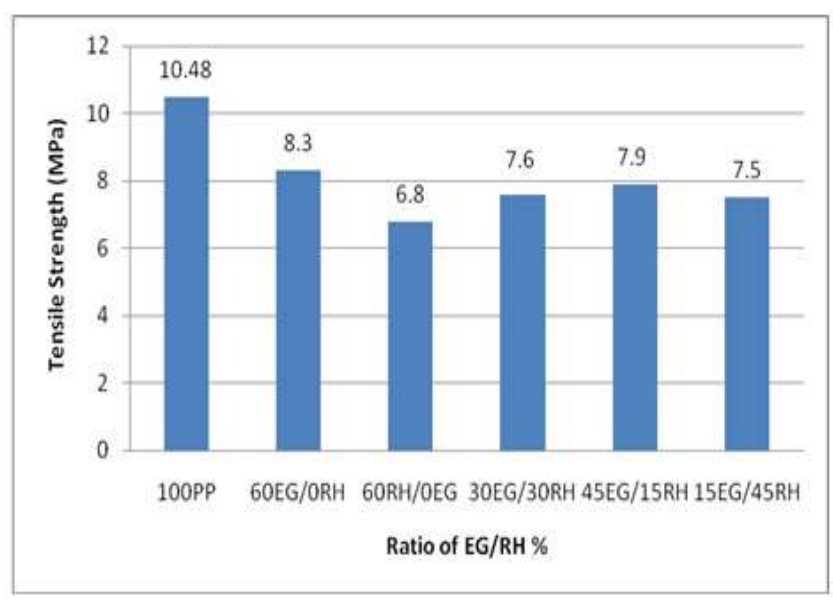

Fig. 9. Chart of Tensile Strength against percentage Hybrid Composition of PP, E-Glass \& Rice Husk 


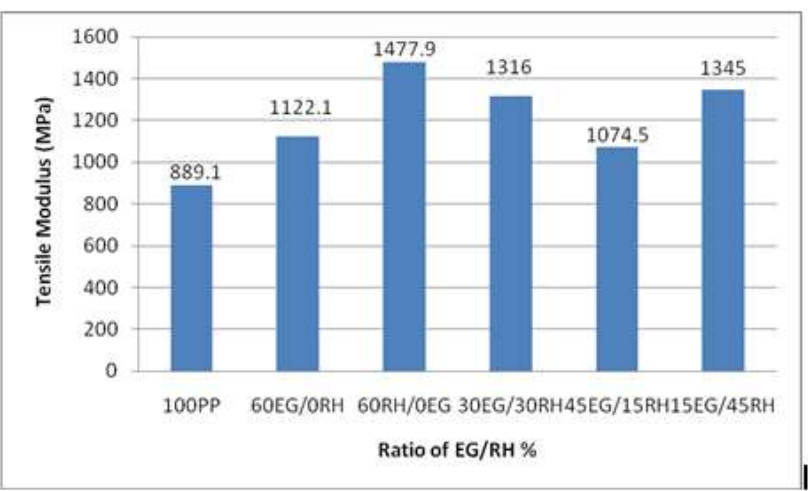

Fig. 10. Chart of Tensile Modulus against percentage hybrid composition of PP, E-Glass \& Rice Husk

\section{B. Hardness Test}

The high hardness value of the mixture shows the property of the material, which has high hardness level. The hardness value of pure PP and hybrid composition PP, E-Glass and rice husk are calculated and shown as in Figure.11. The hardness value of hybrid composite 45 wt. \% rice husk is $10.1 \mathrm{HV}, 30 \mathrm{wt}$ \% rice husk is $8.5 \mathrm{HV}$, and 15 wt. \% rice husk is $8 \mathrm{HV}$ respectively. It can be seen from the result obtained that hardness of treated rice husk increase when the percentage of rice husk increase in hybrid composite. Similar results were reported by [6] addition of rice husk and clay into the thermoplastic increase the hardness. The significant differences in the value shows that the lower percentage of rice husk will decrease the hardness of the material as the bonding between the molecules become irregular. [18] also indicated that, the rice husk fibers increase the value of hardness composites. Increasing rice husk ash loading in natural rubber/linear low density polyethylene increased hardness [17].

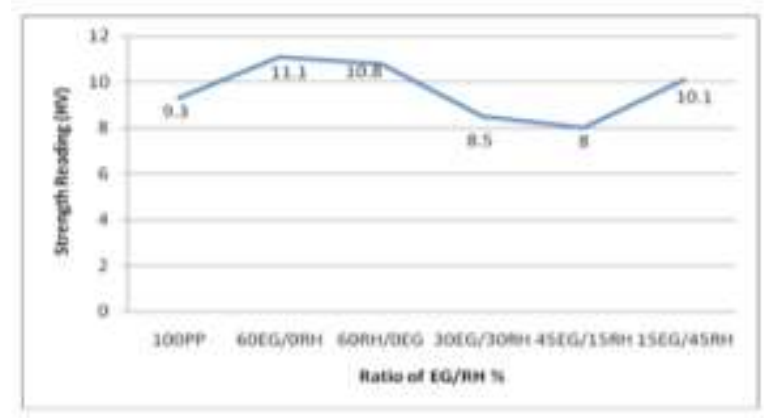

Fig. 11. Graph of microvickers strength against percentage Hybrid Composition of PP, E-Glass \& Rice Husk

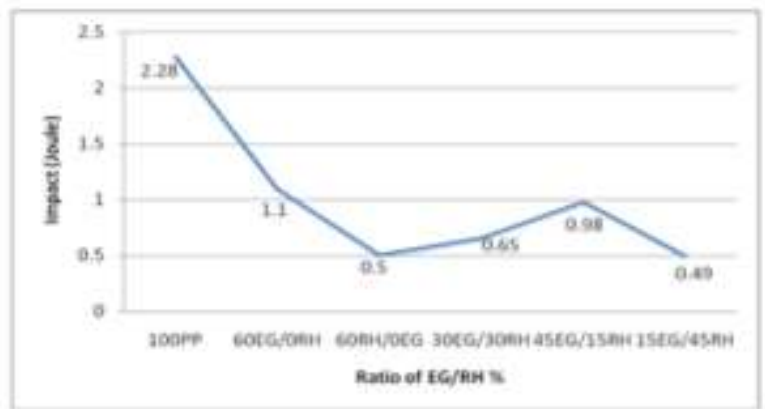

Fig. 12. Graph of Impact Strength against percentage Hybrid Composition of PP, E-Glass \& Rice Husk

\section{Charpy Impact Test}

The impact strength of the hybrid composite PP/EG/RH is presented in Figure 12. Figure 12 shows the impact strength of 15 wt. \% rice husk hybrid mixture is higher than other hybrid mixtures. The impact strength of rice husk composite and hybrid at 60 $\% \mathrm{RH}$ and $15 \% \mathrm{RH}$ wt. \% were $0.5 \mathrm{~J}$ and $0.98 \mathrm{~J}$ respectively. The figure also shows the impact strength is reducing when rice husk \% increase in hybrid composite. It is similar to studies by [19] work on hybrid PP reinforced oil palm empty fruit bunch-glass fiber whereby the hybrid strength decreases as natural fiber content increases. The similar trend is also observed by [15] where the impact strengths were lowered by the addition of rice husk flour. The addition of rice husk and clay into the thermoplastic decrease the impact strength [6]. The addition of rice husk fiber composite generally decreased the impact value [12].

\section{Surface Morphology of Cracked Specimens}

The analyses towards surface morphology of the broken specimens carried out by using scanning electron microscope after the tensile testing. Figure 13 to 16 shows the results. The morphology is used to identify the bonds between the PP/EG/RH hybrid composite structures. It is also used to find the changes on the material after being tested with a strong tensile strength. It is a fact that less percentage of treated rice husk improves the fiber surface bond uniqueness by removing hemicelluloses and producing rough surface in hybrid composite. This topography offers better fiber matrix interface bond and an increase in mechanical properties. 


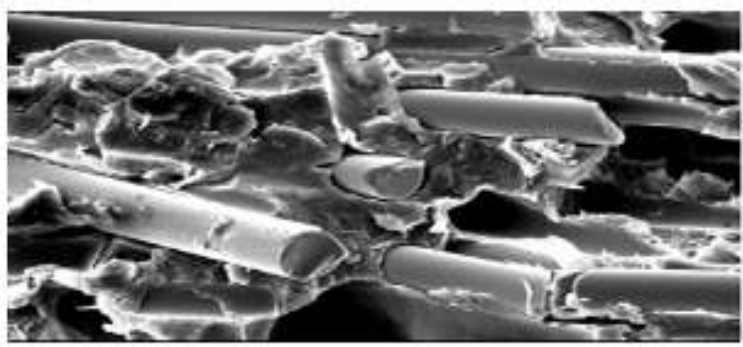

Fig. 13. Magnification at Mixture of 40 wt. \% PP \& 60 wt. $\%$ EG

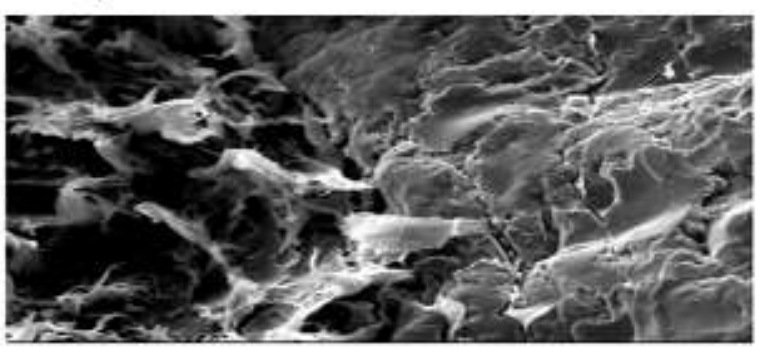

Fig. 14. Magnification at Mixture of 40 wt. \% PP \& 60 wt. $\%$ RH

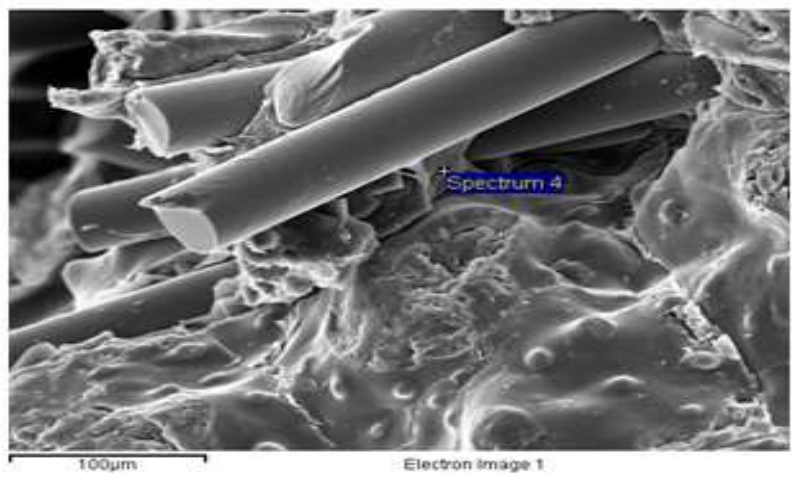

Fig. 15. Magnification at Mixture of 40 wt. \% PP, 45 wt. $\%$ rice husk \& 15 wt. \% E- Glass

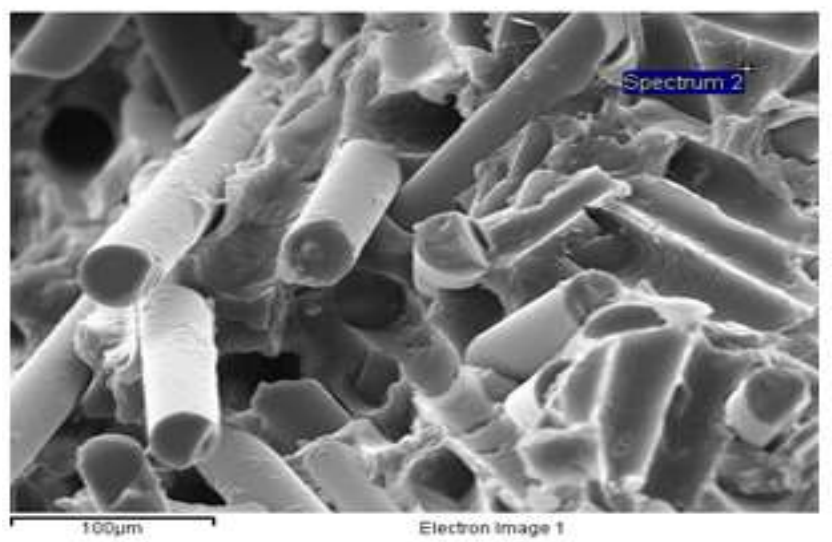

Fig. 16. Magnification at Mixture of 40 wt. \% PP, 15 wt. $\%$ rice husk \& $45 \mathrm{wt}$. \% E- Glass

\section{CONCLUSION}

Based on the mechanical properties results, filling of treated rice husk in the E-Glass/polypropylene hybrid composite degrades the different rates of mechanical testing result. Based on the observation, the best wt. \% mixture for these three materials is $40 \mathrm{wt}$ \% PP, $45 \mathrm{wt}$. $\%$ E-Glass, and 15 wt. \% risk husk for tensile strength and impact strength. Meanwhile, for the tensile modulus and hardness strength is 40 wt. \% PP, 15 wt. \% E-Glass, and $45 \mathrm{wt}$. \% Rice Husk. The morphology test on the broken surface shows that the mixture ratio acknowledged as the factors that are important in improvement the hybrid characteristics.

\section{ACKNOWLEDGMENT}

The authors acknowledge Jabatan Pendidikan Politeknik (JPP) and Universiti Pertahanan National Malaysia (UPNM) for supporting the research work, as well as The Mechanical Engineering Department Polytechnic Port Dickson Negeri Sembilan and The Coordinator of Composite Engineering Laboratory (FKP/UTeM) for granting permission to use all available equipment.

\section{REFERENCES}

[1] Y. My, H. S. IP, J. AR and K. Rassiah, "Mechanical properties of kenaf/polyester composites," International Journal of Engineering \& Technology, vol. 11, no. 1, pp. 127-131, 2011.

[2] S. Kittinaovarat and W. Suthamnoi, "Physical properties of polyolefin/bamboo charcoal composites," Journal of Metals, Materials and Minerals, vol. 19, no. 1, pp. 9-15, 2009.

[3] R. Wirawan, E. S. Zainudin and S. M. Sapuan, "Mechanical properties of natural fibre reinforced PVC composites: A review," Sains Malaysiana, vol. 38, no. 4, pp. 531-535, 2009.

[4] S. K. Majhi, S. K. Nayak, S. Mohanty and L. Unnikrishnan, "Mechanical and fracture behavior of banana fiber reinforced Polylactic Acid biocomposites," International Journal of Plastics Technology, vol. 14 , no. 1 , pp. 57-75, 2010. DOI: 10.1007/s12588-010-0010-6 
[5] K. Rassiah and H. Sihombing, "Effect on mechanical properties of hybrid blended coconut coir/paraffin wax/LDPE," International Journal of Integrated Engineering, vol. 3, no. 2, pp. 63-67, 2011.

[6] I. Ahmad, M. S. M. Jamil and I. Abdullah, "Pengisian sekám padi dan tanah liât ke dalam matriks polietilena berketumpatan tinggi-getah asli-getah asii cecair," Sains Malaysiana, vol. 38, no. 3, pp. 381-386, 2009.

[7] H. G. Premalal, H. Ismail and A. Baharin, "Comparison of the mechanical properties of rice husk powder filled polypropylene composites with talc filled polypropylene composites," Polymer Testing, vol. 21, no. 7, pp. 833-839, 2002. DOI: 10.1016/S01429418(02)00018-1

[8] R. A. Majid, H. Ismail and R. M. Taib, "Effects of polyethylene-g-maleic anhydride on properties of low density polyethylene/thermoplastic sago starch reinforced kenaf fibre composites," Iranian Polymer Journal, vol. 19, no. 7, pp. 501-510, 2010.

[9] H. S. Kim, H. S. Yang, H. J. Kim and H. J. Park, "Thermogravimetric analysis of rice husk flour filled thermoplastic polymer composites," Journal of Thermal Analysis and Calorimetry, vol. 76, no. 2, pp. 395-404, 2004.

DOI: 10.1023/B:JTAN.0000028020.02657.9b

[10] S. Panthapulakkal, M. Sain and S. Law, "Effect of coupling agents on rice-husk-filled HDPE extruded profiles," Polymer International, vol. 54, no. 1, pp. 137142, 2005. DOI: $10.1002 /$ pi.1657

[11] G. R. Liu, "A step-by-step method of rule-of-mixture of fiber-and particle-reinforced composite materials," Composite Structures, vol. 40, no. 3, pp. 313-322, 1997. DOI: 10.1016/S0263-8223(98)000336

[12] M. Razavi-Nouri, F. Jafarzadeh-Dogouri, A. Oromiehie and A. E. Langroudi, "Mechanical properties and water absorption behaviour of chopped rice husk filled polypropylene composites," Iranian Polymer Journal, vol. 15, no. 9, pp. 757-766, 2006.
[13] A. Ashori and A. Nourbakhsh, "Mechanical behavior of agro-residue-reinforced polypropylene," Composites Journal of Applied Polymer Science, vol. 111, no. 5, pp. 2616-2620, 2009. DOI: 10.1002/app.29345

[14] A. Nourbakhsh A. Karegarfard A. Ashori and A. Nourbakhsh, "Properties of medium density fiberboard based on bagasse fibers," Journal of Composite Materials, vol. 43, no. 18, pp. 1927-1934, 2009. DOI: $10.1177 / 0021998309341099$

[15] H. S. Yang, H. J. Kim, J. Son, H. J. Park, B. J. Lee and T. S. Hwang, "Rice-husk flour filled polypropylene composites; Mechanical and morphological study," Composite Structures, vol. 63, no. 3, pp. 305312, 2004. DOI: 10.1016/S0263-8223(03)00179-X

[16] H. Ismail, J. M. Nizam and H. A. Khalil, "The effect of a compatibilizer on the mechanical properties and mass swell of white rice husk ash filled natural rubber/linear low density polyethylene blends," Polymer Testing, vol. 20, no. 2, pp. 125-133, 2001

[17] M. S. Jamil, I. Ahmad and I. Abdullah, "Effects of rice husk filler on the mechanical and thermal properties of liquid natural rubber compatibilized high-density polyethylene/natural rubber blends," Journal of Polymer Research, vol. 13, no. 4, pp. 315-321, 2006. DOI: $10.1007 / \mathrm{s} 10965-005-9040-8$

[18] N. A. Maziad, D. E. El-Nashar and E. M. Sadek, "The effects of a silane coupling agent on properties of rice husk-filled maleic acid anhydride compatibilized natural rubber/low-density polyethylene blend," Journal of Materials Science, vol. 44, no. 10, pp. 2665-2673, 2009. DOI: 10.1007/s10853-009-3349-3

[19] H. D. Rozman, M. J. Saad and Z. M. Ishak, "Flexural and impact properties of oil palm Empty Fruit Bunch (EFB)-Polypropylene composites-The effect of maleic anhydride chemical modification of EFB," Polymer Testing, vol. 22, no. 3, pp. 335-341, 2003. DOI: $10.1016 / S 0142-9418(02) 00109-5$ 